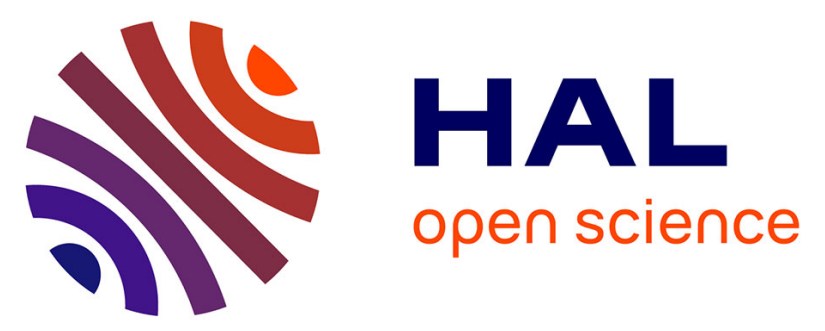

\title{
Comparative lidar study of the optical, geometrical, and dynamical properties of stratospheric post-volcanic aerosols, following the eruptions of El Chichon and Mount Pinatubo
}

Patrick Chazette, Christine David, Jacques Lefrère, Sophie Godin, Jacques

\author{
Pelon, Gérard Mégie
}

\section{To cite this version:}

Patrick Chazette, Christine David, Jacques Lefrère, Sophie Godin, Jacques Pelon, et al.. Comparative lidar study of the optical, geometrical, and dynamical properties of stratospheric post-volcanic aerosols, following the eruptions of El Chichon and Mount Pinatubo. Journal of Geophysical Research: Atmospheres, 1995, 100 (D11), pp.23195-23207. 10.1029/95JD02268 . hal-02902597

\section{HAL Id: hal-02902597 \\ https://hal.science/hal-02902597}

Submitted on 13 Jan 2021

HAL is a multi-disciplinary open access archive for the deposit and dissemination of scientific research documents, whether they are published or not. The documents may come from teaching and research institutions in France or abroad, or from public or private research centers.
L'archive ouverte pluridisciplinaire HAL, est destinée au dépôt et à la diffusion de documents scientifiques de niveau recherche, publiés ou non, émanant des établissements d'enseignement et de recherche français ou étrangers, des laboratoires publics ou privés. 


\title{
Comparative lidar study of the optical, geometrical, and dynamical properties of stratospheric post-volcanic aerosols, following the eruptions of El Chichon and Mount Pinatubo
}

\author{
P. Chazette, C. David, J. Lefrère, S. Godin, J. Pelon and G. Mégie \\ Service d'Aéronomie du CNRS, Institut Pierre-Simon-Laplace, Université Pierre-et-Marie, Paris, France
}

\begin{abstract}
The spatiotemporal evolution of aerosols formed from precursors injected into the stratosphere by major volcanic eruptions, such as those of El Chichon in 1982 and Mount Pinatubo in 1991, has been studied using a ground-based lidar system located at the Observatoire de Haute-Provence (OHP) in southern France $\left(44^{\circ} \mathrm{N}, 5^{\circ} \mathrm{E}\right)$. From the inversion of the lidar signals the optical, geometrical and dynamical properties of the particles have been determined as a function of time after the eruption. In immediate post-volcanic conditions, when the optical thickness of particles in the stratosphere is largely enhanced, an estimate of the aerosols backscatter phase function has been evaluated directly from the lidar measurements, using a sizedistribution model adjusted to in situ balloon measurements. The precision of this determination lies in the $\pm 15 \%$ range. Values of the mean radius of the particles, of their integrated content, surface areas, and sedimentation velocities are then derived from the systematic lidar measurements performed at OHP. These values are compared for the two major volcanic eruptions which have occurred over the last decade. Although the injection of sulphur dioxide was twice as large for the Mount Pinatubo eruption as compared to the El Chichen case, the diffusion of the cloud in the two hemispheres due to the interaction of the particular phase of the quasi-biennal oscillation with several other dynamical processes at the time of the eruption, led to the observation of similar values for the aerosol content over the Observatoire de Haute-Provence in the months just following the two events. However, the residence time of the particles in atmospheric layers below $20 \mathrm{~km}$ are 4 months longer after the Mount Pinatubo eruption, caused by the observed difference in the initial vertical distribution of the aerosol cloud.
\end{abstract}

\section{Introduction}

Major volcanic eruptions inject directly into the stratosphere chemically inert dust particles, characterized by a very short residence time, as well as sulphurous gases, mainly in the form of sulphur dioxide, which are considered as the precursors of aerosol particles, through photochemically induced oxidation processes. The large increase in the amount of stratospheric aerosols due to the major eruptions of El Chichon $\left(17.33^{\circ} \mathrm{N}\right.$, $\left.93.20^{\circ} \mathrm{W}\right)$ in March and April 1982 and Mount Pinatubo $\left(15.14^{\circ} \mathrm{N}, 120.35^{\circ} \mathrm{E}\right)$ in June 1991 , have thus caused major effects on the climate and atmospheric environment of the Earth, including local heating in the stratosphere at altitude levels where aerosols are resident and cooling at the Earth's surface. The heating of the stratosphere, mainly due to the absorption of infrared upwelling radiation is a large-scale phenomena, which corresponded to a $4 \mathrm{~K}$ local temperature increase after the $\mathrm{El}$ Chichon eruption [Labitzke et al., 1983; Hofmann and Rosen, 1987]. Similarly, in September 1991, following the Mount Pinatubo eruption a temperature increase as large as $3.5 \mathrm{~K}$ occurred at the $30 \mathrm{hPa}$ pressure level in a latitude band between the equator and $30^{\circ} \mathrm{N}$ [Labitzke and McCormick, 1992]. The

Copyright 1995 by the American Geophysical Union.

Paper number 95JD02268.

0148-0227/95/95JD-02268\$05.00 absolute amplitude of the temperature decrease at the Earth's surface is smaller as estimated to about $0.5 \mathrm{~K}$ for El Chichon and $0.7 \mathrm{~K}$ for Mount Pinatubo. Nevertheless, such cooling can have a significant climatic impact. Furthermore, since the discovery of the ozone spring depletion in Antarctica and the subsequent importance of heterogeneous chemical processes in the stratospheric ozone balance, sulphate aerosols are considered as potentially playing a major role in the ozone long-term depletion as observed in the middle latitude regions of both hemispheres [Granier and Brasseur, 1992].

In order to quantitatively assess the radiative and chemical influences of large stratospheric aerosol loads, resulting from major volcanic eruptions the microphysical properties of the aerosol particles, that is size distribution, surface area, chemical composition and concentration have to be accurately determined. Although lidar measurements do not constitute an unique mean of determining such properties, they have proven to be quite valuable in assessing their altitude dependence and temporal evolution during the years which follow such major eruptions. Systematic lidar measurements are performed at the Observatoire de Haute-Provence (OHP, $44^{\circ} \mathrm{N}, 5.5^{\circ} \mathrm{E}$ ) since 1980, using a neodymium:yttrium/aluminum/garnet (Nd:YAG) lidar system emitting at $532 \mathrm{~nm}$. These measurements are performed within the context of long term observation of the stratospheric variables, and are thus part of the operation of the Network for Detection of Stratospheric Change. In this frame, 
the aerosol lidar measurements have already been validated as part of several satellite ground validation programs [Lenoble and Brogniez, 1984].

The present study covers the two periods from January 1983 to December 1986, and from October 1991 to December 1993, which correspond to the time periods when the major effects of the El Chichon and Mount Pinatubo volcanic eruptions were observed. It includes a comparative analysis of the spatiotemporal evolution of volcanic aerosols, injected by both eruptions. This analysis is based on the complementarity of lidar remote soundings and in situ balloon measurements [Hofmann and Rosen, 1984a, 1987; Deshler et al., 1993]. As a main result of this study, the backscatter coefficient and the scattering ratio vertical profiles, and the backscatter phase function of the stratospheric aerosol particles at the 532-nm wavelength are determined using an inversion algorithm adapted to lidar measurements in post-volcanic conditions. This algorithm as an adaptation of the widely used Klett's algorithm [Klett, 1981] will be described in section 2. Its sensitivity to the different hypotheses will then be studied. The section 3 will be concerned with the validation of the aerosols optical and geometrical properties as determined from the inversion of the lidar data, and the use of a Mie scattering model. These results are compared to those obtained from lidar measurements at other sites during the same periods and to available balloon data. In section 4 , the temporal evolution of the stratospheric aerosol properties following the major eruptions of El Chichon and Mount Pinatubo are studied and compared in terms of stratospheric residence time of the particles. Furthermore in section 5 , these optical parameters being directly related to the size distribution of the particles, their determination allows to obtain information on the spatiotemporal evolution of the aerosols properties as a function of altitude, including sizc distribution and sedimentation velocity at different altitude levels in the stratosphere. The temporal evolution of the aerosol dynamical properties will be discussed in section 6 using a onedimensional model and will be compared for the El Chichon and Mount Pinatubo eruptions.

\section{Inversion of the Lidar Signals}

The inversion procedure presented here allows the direct determination from lidar measurements of the altitude resolved values of the aerosol backscatter phase function, backscatter coefficient, and scattering ratio. The 532-nm wavelength emitted by the laser, was chosen to minimize absorption in the atmosphere, so that the lidar signal $S(z)$ from the altitude $z$ is only a function of the volumic backscatter and extinction coefficient, respectively, $\beta(z)$ and $\alpha(z)$ [Measures, 1984] :

$$
S(z)=\frac{C}{\left(z-z_{0}\right)} \cdot \beta(z) \cdot \exp \left[-2 \cdot \int_{z_{0}}^{z} \alpha\left(z^{\prime}\right) \cdot d z^{\prime}\right]
$$

where $C$ is a constant which characterizes the overall efficiency of the lidar system implemented at the altitude $z_{0}$. The extinction and backscatter coefficients represent the sum contributions of both Rayleigh scattering by molecules $\left(\alpha_{m}(z)\right.$ and $\left.\beta_{m}(z)\right)$ and scattering by aerosol particles $\left(\alpha_{p}(z)\right.$ and $\left.\beta_{p}(z)\right)$ :

$$
\begin{aligned}
& \alpha(z)=\alpha_{m}(z)+\alpha_{p}(z) \\
& \beta(z)=\beta_{m}(z)+\beta_{p}(z)
\end{aligned}
$$

As usual, scattering by aerosols can also be characterized by the scattering ratio $R(z)$ defined as

$$
R(z)=1+\frac{\beta_{p}(z)}{\beta_{m}(z)}
$$

The determination of $\beta(z)$ from (1) requires the quantitative knowledge of the extinction coefficient $\alpha(z)$. The system to be solved is thus underdetermined, and a second relationship is needed to link together $\alpha(z)$ and $\beta(z)$. If the value of the backscatter phase function is assumed to be known, the following relations can be added :

$$
\begin{aligned}
& \varphi_{p}(z)=\frac{\beta_{p}(z)}{\alpha_{p}(z)} \\
& \varphi_{m}=\frac{\beta_{m}(z)}{\alpha_{m}(z)}
\end{aligned}
$$

where $\varphi_{m}$ is the Rayleigh backscatter phase function normalized for molecular scattering $\left(\varphi_{m}=3 / 8 \pi\right)$, and $\varphi_{p}(z)$ the particles phase function, which depends on the size distribution and refractive index of the aerosols, and can thus vary with altitude.

In the case of the classical inversion procedure for single wavelength lidar measurements, $\varphi_{p}$ is considered as remaining constant with altitude and its value is representative of the altitude where $\beta_{p}(z)$ is maximal. With such an hypothesis, (1) can be solved, as $\beta(z)$ is the solution of a Bernouilli differential equation given by [Klett, 1981, 1985]:

$$
\beta(z)=\frac{\left(z-z_{0}\right)^{2} \cdot S(z) \cdot Q(z)}{\left(z_{r_{t}}-z_{0}\right)^{2} \cdot \frac{S\left(z_{t}\right)}{\beta\left(z_{t}\right)}+\frac{2}{\varphi_{p}} \cdot \int_{z}^{z_{t}}\left(z^{\prime}-z_{0}\right)^{2} \cdot S\left(z^{\prime}\right) \cdot Q\left(z^{\prime}\right) \cdot d z^{\prime}}
$$

with :

$$
Q(z)=\exp \left[2 \cdot\left(\frac{\varphi_{m}}{\varphi_{p}}-1\right) \cdot \int_{z}^{z_{t}} \alpha_{m}\left(z^{\prime}\right) \cdot d z^{\prime}\right]
$$

$z_{t}$ is the reference altitude corresponding to the integration constant of the Bernouilli differential equation. To ensure the mathematical convergence of the solution, the altitude $z_{t}$ has to be chosen above the aerosol layer, where the particle content is negligible. In the remainder of this paper, this reference altitude will be chosen above $30 \mathrm{~km}$, assuming that the scattering ratio $R$ is equal to 1 above this reference altitude. The sensitivity of this hypothesis will be discussed in section 3 .

In the classical case, the determination of the aerosol backscatter coefficient vertical profile $\beta_{p}(z)$ is thus linked to the simultaneous knowledge of both the normalised backscatter phase function $\varphi_{p}$ and the value of $\beta_{p}\left(z_{t}\right)$ at the reference altitude $z_{t}$. It also requires an a priori knowledge of the atmospheric density profile, either through ancillary measurements or using an atmospheric model. However, under particular conditions as discussed below, it is possible to directly estimate the backscatter phase function on the basis of the experimental knowledge of the scattering ratio $R\left(z_{b}\right)$ at a second reference altitude $z_{b}$, provided that at this particular altitude the scattering ratio can be considered as constant. This altitude level will be taken in the upper troposphere. 
The final adjustment of the inverted backscatter profile in this altitude region is then carried out by successive iterations of the relations (4) and (7). The initial value of the normalized backscatter phase function $\varphi_{0}$ is a priori chosen in the interval $\left[\varphi_{\min }, \varphi_{\max }\right]$ which corresponds to the most probable values, taking into account the observed atmospheric conditions (see section 3.2). An altitude profile of the backscatter coefficient is then calculated and its value at the reference altitude $z_{b}$ compared to the reference value $R\left(z_{b}\right)$. A new value of the phase function $\varphi_{p}$ is then chosen in one of the intervals $\left[\varphi_{\text {min }}, \varphi_{0}\right]$ or $\left[\varphi_{0}, \varphi_{\text {max }}\right]$, and the process is iterated until the convergence at the reference altitude $z_{b}$ is obtained within an a priori fixed accuracy. This determines the final value of $\varphi_{p}$. The backscatter phase function and the backscatter coefficient thus determined, are then sensitive to the choice of the two reference altitudes, $z_{t}$ and $z_{b}$, and a quantitative study has to be performed in order to evaluate the different error sources and the remaining uncertainties.

\section{Sensitivity Study : A Priori Assumptions and Uncertainties}

First, the assumptions and the impact of the uncertainty sources associated with the determination of the vertical profile of the stratospheric aerosols backscatter properties will be discussed. This profile is represented by either the backscatter coefficient (3) or the scattering ratio (4). The conditions for an accurate determination of the backscatter phase function will then be further analyzed.

\subsection{Backscatter Vertical Profile}

Uncertainties in the determination of the total backscatter coefficient $\beta(z)$ can be related to five main causes : (1) the statistical fluctuations of the measured signal $S(z)$, associated with random detection processes, (2) the presence of aerosol particles at and above the reference altitude $z_{t}$ and the subsequent uncertainty on the value of $R\left(z_{t}\right)$, (3) the uncertainty on the a priori knowledge of the vertical profile of the Rayleigh backscatter coefficient as determined from ancillary measurements or atmospheric model interpolation, (4) the uncertainty on the value of the phase function $\varphi_{p}$ and on its altitude dependence, and (5) the overall uncertainty resulting from the chosen value of $R\left(z_{b}\right)$ at the lower reference level.

The upper boundary condition used to solve the Bernouilli differential equation (7) assumes the existence of an aerosol free layer at, and above, the altitude $z_{t}$, which is usually chosen close to $30 \mathrm{~km}$. The total volumic backscatter coefficient $\beta\left(z_{t}\right)$ is then reduced to the Rayleigh molecular contribution only. Such an assumption might not be relevant in the months just following the eruption of El Chichon or Mount Pinatubo. Indeed, in 1982, an aerosol layer was observed up to $30 \mathrm{~km}$ [Adriani et al., 1983]. However, such a layer was not detected in the aerosol vertical profiles recorded at OHP from mid-1982 to 1986, and the upper reference altitude was then chosen at $30 \mathrm{~km}$ for the post El Chichon eruption data. Following the eruption of Mount Pinatubo, an aerosol layer was detected in the OHP record at $31 \mathrm{~km}$ altitude. Therefore the upper reference altitude was moved up for the period 1991-1993, with $R\left(z_{t}\right)=1$ at and above $32 \mathrm{~km}$ for the post Mount Pinatubo eruption data.
To quantify the total uncertainty which results from causes (1), (2), and (4), sensitivity calculations have been performed for two different values of the aerosol optical thicknesses 0.24 and 0.04 , respectively, which are within the range of the values experimentally observed following the El Chichon and Mount Pinatubo eruptions. The analytical expressions of the uncertainties on the lidar signals, which are associated with these three different causes, are given in the appendix. They are deduced from (7) and lead to the profiles shown on Figure 1, if the relative uncertainties on the different variables $\left(S(z), \varphi_{p}\right.$, $\left.\beta\left(z_{t}\right)\right)$ are less than $30 \%$. To further reduce the statistical uncertainty on the lidar signals, several individual profiles are averaged to provide a single profile for a given day. The value of the signal to noise ratio at the altitude of the maximum scattering ratio is thus ranging from 40 to 80 , leading to a statistical uncertainty of less than $2.5 \%$. The uncertainty on the scattering ratio at the lower altitudes, that is, below $10 \mathrm{~km}$, associated with the uncertainty on the phase function $\varphi_{p}$ can be considered as low, of the order of $2 \%$ for a relative uncertainty of $20 \%$ on $\varphi_{p}$. This uncertainty further decreases when the altitude increases up to $z_{t}$, where it becomes less than $1 \%$. Thus considering the two algebraic terms of the denominator in (7), the second one, which is dependent on the backscatter phase function, becomes negligible in comparison to the first one as the upper reference altitude $z_{t}$ is approached. In turn, the uncertainty associated with the a priori knowledge of the volume backscatter coefficient $\beta\left(z_{t}\right)$ is the largest one as it remains constant as a function of the optical thickness, while the other uncertainties decrease when the optical thickness increases. Therefore in order to retrieve the backscatter coefficient profiles with a good precision, the uncertainty on $\beta\left(z_{t}\right)$ should be lower than $5 \%$. As already mentioned, the reference altitude $z_{t}$ was thus chosen as high as possible, in order to minimize the uncertainty due to the very low aerosol load at the upper altitude.

Finally, to derive the value of the Rayleigh molecular scattering coefficient, the experimental data following El Chichon eruption were processed using an atmospheric density model, developed at Service d'Aéronomie CNRS from the TIGR (TOVS Initial Guess Retrieval) database [Chedin et al., 1985], which takes into account seasonal fluctuations, while for those following the Mount Pinatubo eruption, the absolute atmospheric density profile was derived from ancillary meteorological radiosoundings. The standard deviation associated with the temperature profiles from TIGR database is $\pm 7.5 \mathrm{~K}$ for midlatitude regions. It induces a relative uncertainty of $3.5 \%$ on the molecular backscatter coefficient, which is further minimized when considering monthly mean values.

\subsection{Backscatter Phase Function}

The determination of the backscatter phase function $\varphi_{p}$ from the lidar measurements requires several assumptions to be taken into account. The first one is to consider the phase function $\varphi_{p}$ as constant with altitude. In section 4.2 , this rather restrictive assumption will be shown to be representative of the altitude range where the backscatter coefficient is maximum, and to lead to derived values in agreement with other in situ and lidar measurements. The second assumption requires the scattering ratio $R(z)$ to remain close to 1.05 at the lower reference level $z_{b}$, which is usually taken between 8 and $9 \mathrm{~km}$. Such a value of the 

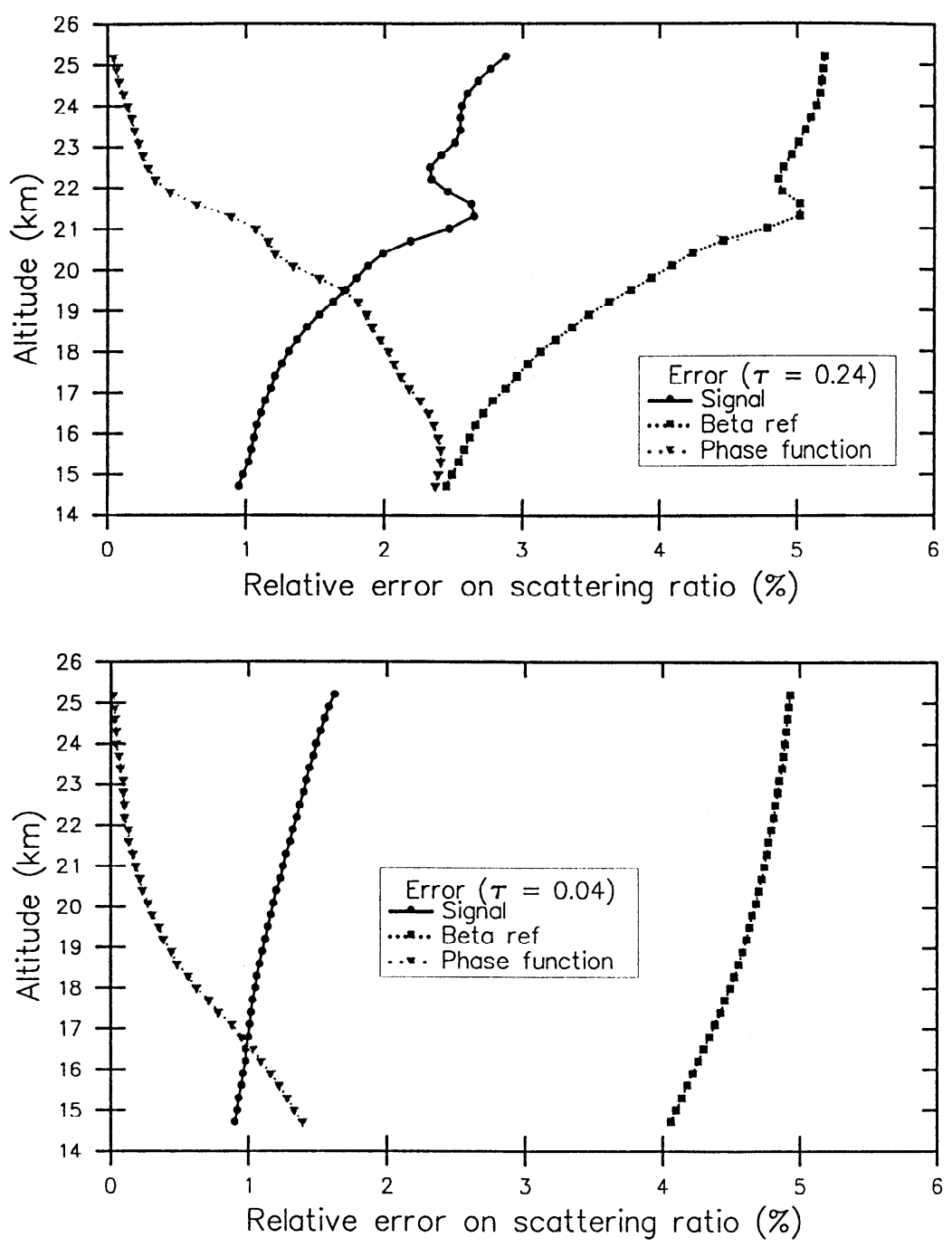

Figure 1. Evolution of the different error sources as a function of altitude for (a) January 1, 1983, and (b) January 1, 1985. The three sources of error represented are those associated with the signal-to-noise ratio, the value of the backscatter coefficient at the reference altitude, and the backscatter phase function.

scattering ratio in this altitude range corresponds to a maximum value including the values experimentally observed for background aerosol level [Russell et al., 1979] and post-volcanic situations in the lower stratosphere. From Menzies and Tratt [1995] measurements, values of $R\left(z_{b}\right)$ between 1.03 and 1.05 are observed between 8 and $13 \mathrm{~km}$, in post-Pinatubo conditions. Therefore the scattering ratio cannot be overestimated by more than $5 \%$. Figure 2 gives the relative variation of $\varphi_{p}$ from an initial value of $0.02 \mathrm{sr}^{-1}$, as a function of the deviation of $R\left(z_{b}\right)$ from 1.05. As $\varphi_{p}$ depends on the extinction of the particles and thus on their optical thickness, these variations are represented for different values of the optical thickness. Figure 2 shows that the uncertainty on $\varphi_{p}$ is a decreasing function of the optical thickness $\tau$, leading to quite large values of the uncertainty when $\tau$ is less than 0.05 . Furthermore, for the low values of the optical thickness, uncertainties associated with the lower boundary condition at the reference altitude $z_{b}$ have a significant impact at the lower edge of the backscatter lidar profile (Figure 1) and the evaluation of $\varphi_{p}$ may thus be greatly affected. The detcrmination of the stratospheric aerosols backscatter phase function will therefore only be possible, with a sufficient level of confidence, in a post-volcanic situation, as we shall see.

The possible a priori values of the backscatter phase function $\varphi_{p}$ will be in the range $\left[0.013 \mathrm{sr}^{-1}-0.030 \mathrm{sr}^{-1}\right]$. This interval shown in Figure 6 is deduced from Ackerman et al. [1989] results and Mie scattering theory (see section 5). In the procedure which had been applied to the lidar data (see section 2), the backscatter phase function $\varphi_{p}$ chosen in the previous interval, will be considered as constant with altitude. Such an assumption also implies that stratospheric particles are spread out uniformly over altitude. To test this assumption, balloon measurements of the particle size distributions, performed at various locations by Hofmann and Rosen [1983, 1984b, 1987] after the eruption of El Chichon and by Deshler et al. [1993] after the eruption of Mount Pinatubo, can be considered. From these measurements of the vertical profiles of the particles size distribution, one can assess that the observed size distribution of the particles remained constant with altitude, for both El Chichon and Mount Pinatubo reference periods. To be more specific, measurements taken at Laramie, Wyoming 


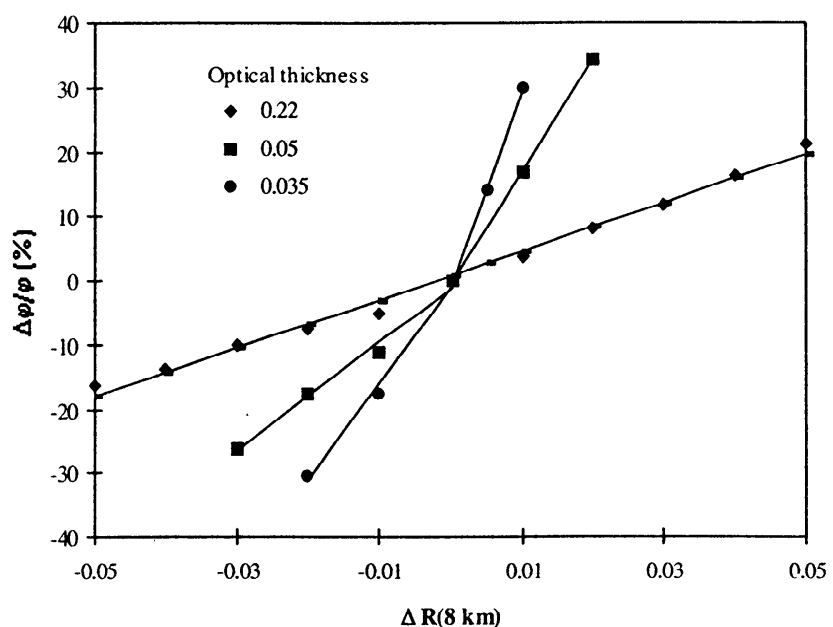

Figure 2. Relative errors on the backscatter phase function $\varphi_{p}$ as a function of the absolute error on the scattering ratio at the reference altitude $(8 \mathrm{~km})$.

$\left(41^{\circ} \mathrm{N}\right)$, show that the ratio of the concentration of particles with a radius larger than $0.15 \mu \mathrm{m}$ to those with a radius larger than $0.25 \mu \mathrm{m}$ remains constant with altitude, with an average value of 2 for the El Chichon event and 2.25 for the Mount Pinatubo event.

\section{Compared Evolution of the Scattering Properties of the El Chichon and Mount Pinatubo Aerosol Clouds}

The results presented here have been obtained from a collection of 250 daily measurements made at the Observatoire de Haute-Provence between January 1983 and December 1986 following the $\mathrm{El}$ Chichon eruption and 137 daily lidar measurements following the eruption of Mount Pinatubo from June 1991 to July 1993. As already mentioned, the individual lidar profiles obtained in $2 \mathrm{~min}$ were averaged and filtered to improve the signal-to-noise ratio. Respectively, the temporal resolution is reduced to 1 hour and the vertical resolution is reduced to $900 \mathrm{~m}$. In addition, monthly averages have also been determined in order to filter out the small-scale temporal and vertical fluctuations, and sporadic effects linked to horizontal transport. The inversion procedure presented previously was then applied on the monthly values to determine the scattering characteristics of the stratospheric aerosol layers, including the backscatter phase function.

\subsection{Scattering Ratio, Backscatter Coefficient, and Residence Times of the Volcanic Aerosol Particles}

Figure 3 represents the temporal variations of the volume backscatter coefficient integrated over the entire altitude range where aerosols have been detected and of the quantity $\left(R_{m}-1\right)$ for the two events. $R_{m}$ is the maximum of the scattering ratio vertical profile. Figures 4 and 5 also represent the temporal evolution of the volume backscatter coefficient integrated over two different altitude ranges from 15 to $20 \mathrm{~km}$ and 20 to 25 , respectively, for the El Chichon and Mount Pinatubo eruptions.

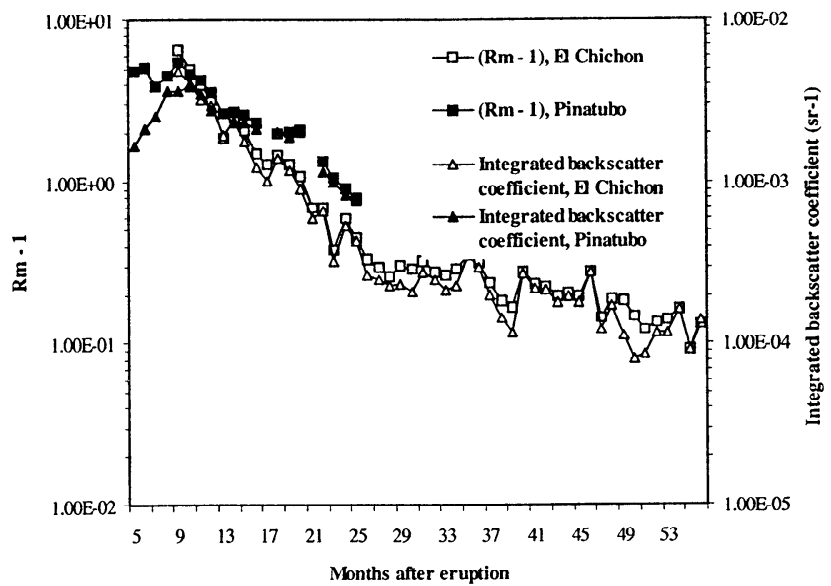

Figure 3. Temporal evolution of the scattering ratio $\left(R_{\max }-I\right)$ and of the integrated backscatter coefficient between $15-20$ and 20-25 km for the El Chichon event.

The maximum value measured at the Observatoire de HauteProvence for the quantity $\left(R_{m}-1\right)$ appears to be the same for the two events, and the maximum backscatter coefficient integrated over the whole altitude range where aerosols particles are present, is also close for the Mount Pinatubo eruption (3.9 $10^{-3} \mathrm{sr}^{-1}$ in April-May 1992) and for the El Chichon event (4.9 $10^{-3} \mathrm{sr}^{-1}$ in January 1983). Although the total mass of sulphur dioxide injected in the stratosphere for the Mount Pinatubo eruption was twice as large as the one due to the $\mathrm{El}$ Chichon eruption. One has to take into account the fact that the two eruptions occurred at different temporal phases of the quasibiennal oscillation (QBO), and that the $\mathrm{QBO}$, in association with other dynamical processes, such as the Asian Monsoon, transient planetary waves, stratospheric anticyclonic systems [Trepte et al., 1993], or aerosol heating secondary induced circulation [Young et al., 1994], drives the meridional circulation in the tropical stratosphere. Therefore, the Mount Pinatubo cloud was dispersed simultaneously in both hemispheres, although the El Chichon cloud dispersion was restricted to the northern hemisphere only during several months.

An important variable to quantify the potential impact of the post-volcanic aerosol layers is the $e$-fold residence time of the

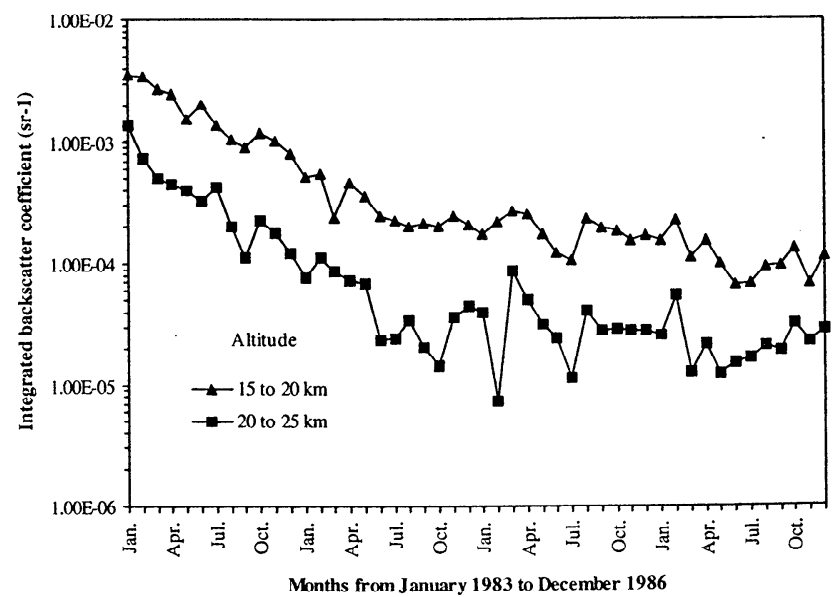

Figure 4. Temporal evolution of the scattering ratio $\left(R_{\max }-1\right)$ and of the integrated backscatter coefficient between 15-20 and $20-25 \mathrm{~km}$ for the Pinatubo event. 


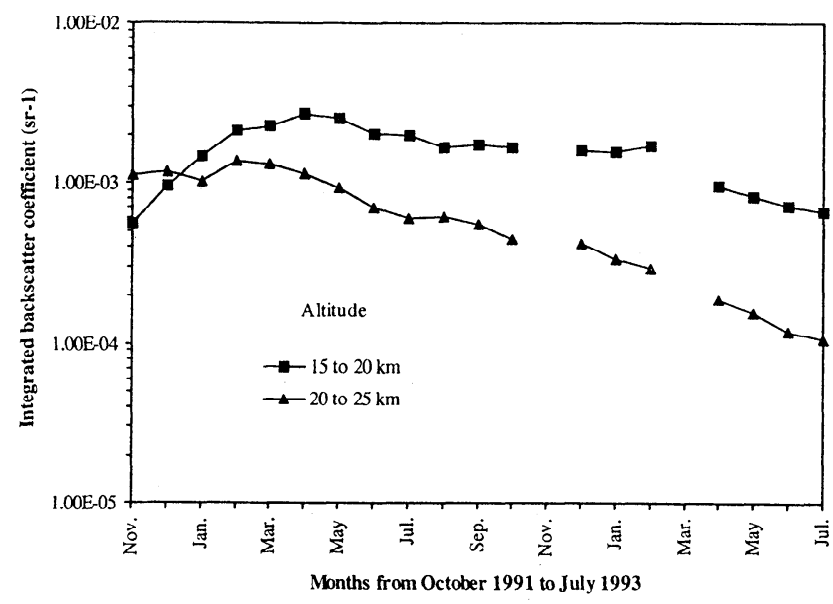

Figure 5. Temporal evolution of the integrated backscatter coefficient between $15-20 \mathrm{~km}$ and $20-25 \mathrm{~km}$ for the El Chichon and Mount Pinatubo events.

particles as determined from the time evolution of the maximum scattering ratio $R_{m}$. The term "residence time" is not altogether justified here, since the reduction in the aerosol load at a given site is associated with the combined effects of change in the aerosol composition, horizontal and vertical diffusion, and sedimentation processes. The first two effects play a determining role in the first months which follow the injection of gases in the stratosphere. One can then consider that the aerosol clouds became homogeneous both in composition and in latitudinal distribution between 6 and 10 months following the eruption. The former value is certainly appropriate for the Mount Pinatubo event [MCCormick and Veiga, 199'2], the latter one being closely related to the El Chichon event [Michalsky et al., 1984]. Therefore the residence times will be determined starting respectively in March 1983 for El Chichon eruption and in April 1992 for the Mount Pinatubo eruption.

Figures 3 and 4 show, for the El Chichon event, the temporal variations of the quantity $\left(R_{m}-1\right)$ and of the volume backscatter coefficient integrated over the altitude range $15-20 \mathrm{~km}$, where the largest value of the scattering ratio are observed, and in the uppermost layer between 20 and $25 \mathrm{~km}$. The observed temporal decrease in the lower layer is exponential for the period March 1983 to August 1984, leading to an $e$-fold residence time of 8 months. Similar values of 7 and 7.6 months, respectively, were observed using lidar measurements at $0.532 \mu \mathrm{m}$ and $0.355 \mu \mathrm{m}$ at Aberystwyth $\left(42.5^{\circ} \mathrm{N}, 4.1^{\circ} \mathrm{W}\right)$ [Thomas et al., 1987], and by Hofmann and Rosen [1984a] for the total mass burden above $15 \mathrm{~km}$. When considering the upper layer $(20-25 \mathrm{~km})$, a similar residence time was found.

Several other minor volcanic eruptions which occurred from 1983 on, can also have affected the temporal variation of the scattering ratio values as observed at OHP. In October 1983, the observed maximum scattering ratio increased by nearly $10 \%$, probably in relation with the eruption of the volcano Una Una $\left(0.17^{\circ} \mathrm{S}, 124.42^{\circ} \mathrm{E}\right)$ in July 1983 . The effects of the eruptions of the volcanoes Miyakejima $\left(34.08^{\circ} \mathrm{N}, 139.53^{\circ} \mathrm{E}\right)$ which erupted in September 1983 and of the Mount Pavlov $\left(55.42^{\circ} \mathrm{N}\right.$, $161.9^{\circ} \mathrm{W}$ ), which erupted in February 1984 , were only detected as from March 1985 on. These eruptions led to increases of the maximum scattering ratio of about $15 \%$ at $18 \mathrm{~km}$ and a second aerosol layer was detected at an average altitude of $22 \mathrm{~km}$. The existence of these two layers is further confirmed by other lidar measurements performed at the same latitude [Jäger and Carnuth, 1987].

Figures 3 and 5 show the same quantities, as measured after the eruption of Mount Pinatubo in June 1991. The Mount Pinatubo cloud was first observed at Observatoire de HauteProvence on July 1, 1991, at an average altitude of $16 \mathrm{~km}$. A double layered structure $(16-18 \mathrm{~km})$ appeared at the end of July and was maintained until the end of August. The main cloud was observed at $24 \mathrm{~km}$ on October 1, 1991, with scattering ratios as large as 18 at $532 \mathrm{~nm}$. These observations are in agreement with the latitudinal redistribution of the stratospheric cloud as observed from both ground-based and satellite measurements [Trepte et al., 1993]. The vertical mixing of the various aerosol layers can be considered as complete as early as mid-November 1991. Until May 1992, the maximum values of the scattering ratios are observed in the upper most layer above $20 \mathrm{~km}$. This observation directly relates to the magnitude of the Mount Pinatubo eruption as compared to the El Chichon one, and to the higher injection altitude of the initial cloud. Accordingly, the residence times determined from the temporal evolution of the integrated backscatter coefficient are larger than the ones derived for the El Chichon event : 7 months in the upper layer (20-25 km) and 12 months in the lower layer (15-20 $\mathrm{km})$. The large difference between the El Chichon and Mount Pinatubo observed residence times in the 15 to $20-\mathrm{km}$ altitude layer, can also be explained by the different vertical distribution of the particles in the upper layer. For the El Chichon eruption, the particles were mainly concentrated in the most lower part of the upper layer, and the sedimentation processes were then faster (see section 6). In addition, the increase in the mass of the particles by coalescence processes could also lead to a more rapid sedimentation toward the lower altitudes.

\subsection{Temporal Evolution of the Backscatter Phase Function}

Using the inversion method described in section 2, the temporal evolution of the normalized backscatter phase function $\varphi_{p}$, has also been determined for the two events, with a difference being observed in the retrieved values. When considering the period following the El Chichon eruption, the average value retrieved from the lidar data in 1983 is equal to $0.023 \pm 0.003 \mathrm{sr}^{-1}$, whereas, when performing the same inversion on the data from the years 1984 and 1985, a value of $0.016 \pm 0.004 \mathrm{sr}^{-1}$ is obtained. The 1983 value is in rather good agreement, although at the lower edge, with some of the values reported from other lidar measurements, which range from $0.017 \mathrm{sr}^{-1}$ to $0.045 \mathrm{sr}^{-1}$ for stratospheric particles between 10 and $30 \mathrm{~km}$ [Jäger and Hofmann, 1991; Thomas et al., 1987]. A similar decrease in the backscatter phase function over the period 1983-1985 has also been reported by Jäger and Hofmann [1991], from a combination of lidar and in situ balloon measurements in the middle latitudes of the northern hemisphere, although the absolute values of the phase function for the period 1984-1985 $\left(0.024 \mathrm{sr}^{-1}\right)$ are still larger than the one derived from single wavelength lidar measurements at OHP. The backscatter phase function can also be derived from the particle size distribution as determined from the SAGE II satellite measurements [Ackerman et al., 1989]. The observed values for the period 1984-1985 range from $0.013 \mathrm{sr}^{-1}$ to 0.025 $\mathrm{sr}^{-1}$, and are again compatible with the lidar derived values at 
OHP, especially if one takes into account the fact that since the end of 1984, the optical thickness of the aerosol layer is less than 0.015 , leading to an increasing error on the derived backscatter phase function of the order of $40 \%$. A comparison between these values of the backscatter phase function and the values obtained from other measurements is presented in Table 1. The implication of this change in the particle backscatter phase function will be further discussed in terms of size distribution in the section 5 .

The backscatter phase function $\varphi_{p}$, has also been derived for the Mount Pinatubo aerosol particles, over the period October 1991 to July 1993 . The main result is that the value of $\varphi_{p}$, is constant throughout the whole period, equal to $0.025 \pm 0.003 \mathrm{sr}^{-1}$. This result is well in the range of the reported values from in situ balloon measurements, in which the phase function is derived from the measured size distribution of the particles. Such values range from $0.037 \mathrm{sr}^{-1}$ to $0.015 \mathrm{sr}^{-1}$ [Deshler et al., 1993] for the altitude range between 17 and $23 \mathrm{~km}$. The size distribution determined by Deshler et al. [1993] at $19 \mathrm{~km}$ altitude, where the backscatter coefficient is maximum, leads to a value of the phase function close to $0.026 \mathrm{sr}^{-1}$ (see Table 1).

\section{Determination of the Size Distribution, Number Density and Surface Area of the Volcanic Clouds Particles}

In terms of microphysical properties and chemical composition, the aerosol particles reached a "pseudo-stationary" state in the months following the eruptions. This state corresponds to sulphate particles made of sulphuric acid in aqueous solution. At least $70 \%$ of the particles present in the stratosphere were of this composition in early 1983 after the eruption of El Chichon [Rosen and Hofmann, 1986], and at least $50 \%$ about 2 months after the eruption of Mount Pinatubo [McCormick and Veiga, 1992]. Their refractive index at the wavelength of the lidar measurements, that is, $532 \mathrm{~nm}$, can thus be taken between 1.43 and 1.44 (assuming $75 \%$ by weight for sulphuric acid aerosol composition, Palmer and Williams [1975]) and remained relatively constant with time. The size distribution of the aerosol particles can in turn be determined from single wavelength lidar measurements, only if such an a priori knowledge of the nature and composition of the particles is given. Furthermore, one generally assumes that this size distribution can be represented by a single analytical function, which is considered as valid over the whole altitude range. As such, the lognormal distribution can be considered as representative of the stratospheric aerosol particles [Lenoble et al., 1984; Rosen and Hofmann, 1986; Deshler et al., 1993]. It is given by the following equation :

$$
n(r)=\frac{1}{r \cdot \sqrt{2 \pi} \cdot \ln \sigma} \cdot \exp \left(-\frac{\ln \frac{r}{r_{m}}}{2 \ln \sigma}\right)
$$

where $n(r)$ is the relative number of particles of radius $r$ between $r$ and $r+d r, \sigma$ the dispersion around the modal radius $r_{m}$. The effective radius $r_{\text {eff }}$, which is also used to characterize the particle size distribution is then given as a function of $r_{m}$ by:

$$
r_{\text {eff }}=r_{m} \cdot \exp \left[2.5 \cdot\left(\ln ^{2} \sigma\right)\right]
$$

From the knowledge of the characteristic values of the particle size distribution, one can then determine the integrated number density $N$ (particles. $\mathrm{cm}^{-2}$ ) of the particles in a given altitude interval, which is of particular interest for the radiative impact of the volcanic cloud, and the total surface area $S$ $\left(\mu \mathrm{m}^{2} . \mathrm{cm}^{-3}\right)$ of the particles as a function of altitude, which is relevant to their chemical impact in terms of heterogeneous processes linked to the ozone depletion problem.

The quantity derived from the lidar measurements is the backscatter phase function $\varphi_{p}$ which can be calculated as a function of $r_{\text {eff }}$ and $\sigma$ using the Mie scattering theory, only valid for spherical particles, and assuming the lognormal size distribution as defined above and a real value of the refractive index of the particles equal to 1.44 . The result of this calculation is represented on the Figure 6, showing a minimum value of the phase function for an effective radius of $0.18 \mu \mathrm{m}$. Therefore a given value of $\varphi_{p}$ corresponds to two different values of $r_{\text {eff }}$ for a given value of $\sigma$. However, the relevant part of the function corresponds to the values of $r_{\text {eff }}$ larger than the particular value corresponding to the minimum $\varphi_{p}$, since usually reported values of the volcanic aerosol particles effective radius are larger than $0.2 \mu \mathrm{m}$ [Ackerman et al., 1989]. Nevertheless, the simultaneous determination of $r_{\text {eff }}$ and $\sigma$ cannot be done using the only value of $\varphi_{p}$ as derived from the single wavelength backscatter lidar measurements. To solve this underdetermination of the system, an additional characteristic variable of the size distribution of the particles has to be determined from ancillary measurements. This is done using the in situ balloon measurements performed at the same latitude by IIofmann and Rosen [1987] and Deshler et al. [1993]. In order to reduce the dependence and the uncertainty related to the balloon measurements, one will use a global parameter to characterize the size distribution, that is, the ratio $R_{N}$ defined by :

$$
R_{N}=\frac{n_{0.15}}{n_{0.25}}
$$

\begin{tabular}{|c|c|c|c|}
\hline Years & 1983 & $1984 / 1985$ & 1991 to 1993 \\
\hline $\begin{array}{l}\text { Our values } \\
\text { Other values }\end{array}$ & $\begin{array}{l}0.023 \mathrm{sr}^{-1} \\
0.017 \mathrm{sr}^{-1} \text { to } 0.045 \mathrm{sr}^{-1} \\
\text { [Jäger and Hofmann, } \\
\quad \text { 1991] } \\
\text { [Thomas et al, 1987] }\end{array}$ & $\begin{array}{c}0.016 \mathrm{sr}^{-1} \\
0.024 \mathrm{sr}^{-1} \\
\text { [Jäger and Hofmann, } \\
1991] \\
0.013 \text { to } 0.025 \mathrm{sr}^{-1} \\
\text { [Ackerman et al, 1989)] }\end{array}$ & $\begin{array}{c}0.025 \mathrm{sr}^{-1} \\
0.015 \mathrm{sr}^{-1} \text { at } 17 \mathrm{~km} \\
0.026 \mathrm{sr}^{-1} \text { at } 19 \mathrm{~km} \\
0.015 \mathrm{sr}^{-1} \text { at } 23 \mathrm{~km} \\
{[\text { Deshler et al, } 1993]}\end{array}$ \\
\hline
\end{tabular}

Table 1. Values of the Backscatter Phase Function for 3 Periods of Time Following the El Chichon and Mount Pinatubo Eruptions 


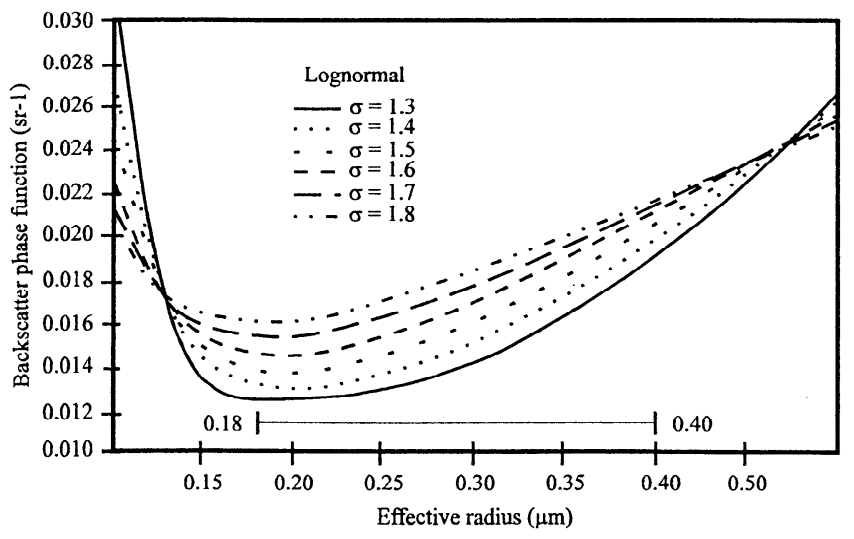

Figure 6. Variation of the normalized backscatter phase function with the effective radius $r_{\text {eff }}$ and the dispersion $\sigma$ of the lognormal size distribution being considered.

where $n_{x}$ represents the particles number density with an effective radius smaller than $x$. Figure 7 then represents, as a function of $r_{\text {eff }}$ and $\sigma$, the curves corresponding to the two values of $\varphi_{p}$ determined from the lidar measurements $\left(\varphi_{p}=0.016\right.$ and $\left.0.023 \mathrm{sr}^{-1}\right)$, and the curves corresponding to characteristics values of $R_{N}$ as given by the balloon measurements. From these curves, the size distribution of the aerosol particles can be determined for both events. For the El Chichon event, the value of $R_{N}$ as measured by Hofmann and Rosen [1987] varies from 1.6 in carly 1983 to 2 in mid-1983 and remains then constant. For the Mount Pinatubo event, vertical aerosol profiles as measured by Deshler between November 1991 and December 1992 [Deshler et al., 1993] yield to a relatively constant value of $R_{N}$ around 2.25. The parameters of the particles size distribution for all the considered periods, as determined using the curves represented on the Figure 7 are summarized in Table 2, with the relative errors as calculated from the sensitivity analysis performed in section 3 .

The integrated number of particles following the El Chichon eruption in the altitude ranges $15-20 \mathrm{~km}$ and $20-25 \mathrm{~km}$ are represented on Figure 8 and compared to those obtained from balloon measurements by Hofmann and Rosen [1987]. In general, the values derived from lidar measurements are larger than the ones derived directly from the balloon measurements although the agreement is rather good for the year 1983 in the

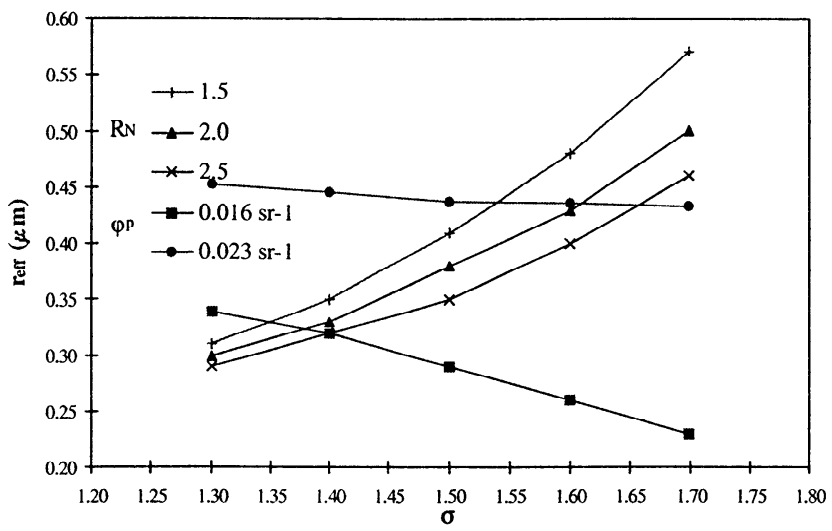

Figure 7. Variations of the quantity $R_{N}$ (see text) and of the normalized backscatter phase function as a function of the effective radius $r_{\text {eff }}$ and of the dispersion $\sigma$. upper most layer. The average surface area per unit volume available for chemical processing on aerosol surfaces is given in Table 3 for the two altitude ranges and for the two periods of reference, that is, 1983 and 1984-1985. A large decrease in the available surface areas is observed in the later period.

The same variables as derived for the period following the Mount Pinatubo eruption are represented in Figure 9 and in Table 3. The maximum integrated content was clearly observed in the upper layer in October and November 1991. For the period from October 1991 up to March 1993, these integrated aerosol contents correspond to a particle number density of 6-29 particles. $\mathrm{cm}^{-3}$ for the 15 to $20-\mathrm{km}$ layer and $1-15$ particles. $\mathrm{cm}^{-3}$ for the 20 to $25-\mathrm{km}$ layer. Similar values of $10-15$ particles. $\mathrm{cm}^{-3}$ for the altitudes of 17 and $19 \mathrm{~km}$ and of 5-11 particles. $\mathrm{cm}^{-3}$ for the altitudes of 21 and $23 \mathrm{~km}$, have been reported by Deshler et al. [1993] in close agreement with the lidar data. The surface areas of the particles are comparable to the values obtained following the El Chichon eruption (see Table 3), with larger values being obtained at lower altitudes as a result of coalescence and sedimentation processes.

\section{Sedimentation Processes and Residence Times}

The particles residence times which have been derived from the lidar measurements (section 4) are partly related to vertical sedimentation processes, characterized by a mean velocity which can be directly derived from the geometrical characteristics of the particles. Using Stokes law, this velocity is expressed, for particles with a radius of less than $80 \mu \mathrm{m}$, as [Whitten, 1982] :

$$
\bar{V}=\frac{2}{9} \cdot \frac{\rho_{p}(z)-\rho_{a}(z)}{\mu(z)} \cdot g(z) \cdot C(z) \cdot \overline{r^{2}}
$$

where $z$ is the altitude, $\rho_{a}(z)$ is the density of air, $\rho_{p}(z)$ is the density of the particles, $\mu(z)$ is the dynamical viscosity of air, $g(z)$ is the acceleration of gravity, and $\overline{r^{2}}$ is the average quadratic radius of the particles. The Cunningham factor $C(z)$ is defined by

$$
C(z)=1+K \cdot \frac{l(z)}{\bar{r}}
$$

where $K$ is a constant $(0.80 \leq K \leq 0.86)$ and $l(z)$ is the particles mean free path. The average radius $\bar{r}$ and the average quadratic radius $\overline{r^{2}}$ of the particles are given for a a lognormal size distribution, by

$$
\begin{aligned}
& \bar{r}=r_{\text {eff }} \cdot \exp \left[-2 \cdot(\ln (\sigma))^{2}\right] \\
& \overline{r^{2}}=r_{e f f}^{2} \cdot \exp \left[-3 \cdot(\ln (\sigma))^{2}\right]
\end{aligned}
$$

Using the characteristic values of the size distribution of the particles related to the El Chichon and Pinatubo eruptions as derived in section 5 , one can then calculate the sedimentation velocities for the two altitude layers already defined $(15-20 \mathrm{~km}$, 20-25 km). These values are given in the Table 4. The decrease in the sedimentation velocities of the particles from 1983 to 1984 is directly related to the decrease in their mean quadratic 
Table 2. Values of the Effective Radius $r_{\text {eff }}$ and of the Dispersion $\sigma$ of Stratospheric Aerosol Particles in the Altitude Range from 15 to $25 \mathrm{~km}$, for 3 Periods of Time Following the El Chichon and Mount Pinatubo Eruptions

\begin{tabular}{ccccc}
\hline Period & $\mathrm{r}_{\text {eff }}(\mu \mathrm{m})$ & $\Delta \mathrm{r}_{\text {eff }} / \mathrm{r}_{\text {eff }}$ & $\sigma(\mu \mathrm{m})$ & $\Delta \sigma / \sigma$ \\
\hline El Chichon 1983 & 0.44 & $2 \%$ & 1.6 & $5 \%$ \\
El Chichon 1984-1985 & 0.32 & $20 \%$ & 1.4 & $10 \%$ \\
Mount Pinatubo 1991-1993 & 0.45 & $15 \%$ & 1.7 & $10 \%$ \\
\hline
\end{tabular}

radius. For both events, the sedimentation velocity in the upper layer is about $50 \%$ larger than the one calculated for the lower layer. In fact, the altitude dependence for the dynamical viscosity, of the acceleration of gravity and of the density difference $\left(\rho_{p}-\rho_{a}\right)$ is quite small between 15 and $25 \mathrm{~km}$. Therefore the sedimentation velocity is directly proportional to the mean free path and can be expressed as

$$
\begin{array}{r}
\bar{V}(z) \approx a \cdot\left[\overline{r^{2}}+K \cdot l_{0} \cdot \bar{r} \cdot \exp \left(\frac{z-z_{0}}{H}\right)\right] \\
\text { with } a=\frac{2}{9} \cdot \frac{\rho_{p}(z)}{\mu(z)} \cdot g(z)
\end{array}
$$

where $l_{0}$ is the mean free path at the altitude $z 0$.

In order to more quantitatively assess the temporal evolution of the distribution of the backscatter coefficient $\beta(z)$ in the two altitude layers already defined (that is, $15-20 \mathrm{~km}, 20-25 \mathrm{~km}$ ), a one-dimensional box model has been used based on the continuity equation and the expression (16) of the sedimentation velocity. If one assumes that the backscatter cross section is constant over the two time periods considered (1983-1984, 1992-1993), the evolution of $\beta(z)$ also describes the evolution of the particles number density. However, when describing the vertical motion of the particles, one should also take into account the vertical flux due to eddy diffusion, which can be parametrized in terms of an average vertical eddy diffusion coefficient $K_{z}$ defined for the altitude range $15-20 \mathrm{~km}$ as equal to $0.5 \mathrm{~m}^{2} \mathrm{~s}^{-1}$ and for the altitude range $20-25 \mathrm{~km}$ as equal to $0.01 \mathrm{~m}^{2} \mathrm{~s}^{-1}$. These mean values of eddy diffusion coefficient are closed to the average values respectively considered by Brasseur and Solomon [1984] and by Shibata et al. [1984] for the summertime. However, this simple model does not take into account the horizontal transport from equatorial and polar latitudes, which could lead to an additional source of aerosols particles in the middle latitude region. Yet, for the time period considered here, the horizontal equilibrium of the global aerosol layer in terms of horizontal transport could be considered as already reached. In addition, any sporadic effects, which in fact are not observed when considering the individual daily profiles, would be further attenuated by using monthly mean scattering ratio and backscatter coefficient profiles.

In the upper layer $(20-25 \mathrm{~km})$, the eddy diffusion processes can be considered as negligible as compared to the sedimentation processes, the flux associated to the sedimentation being larger by more than 1 order of magnitude. The continuity equation which describes the temporal evolution of $\beta(z)$ following the El Chichon and Mount Pinatubo eruptions is then integrated with a 1 week time step and a $1-\mathrm{km}$ altitude step similar to the vertical resolution of the lidar measurements. The initial conditions are directly derived from the observations in December 1982 and October 1991. The model has been run

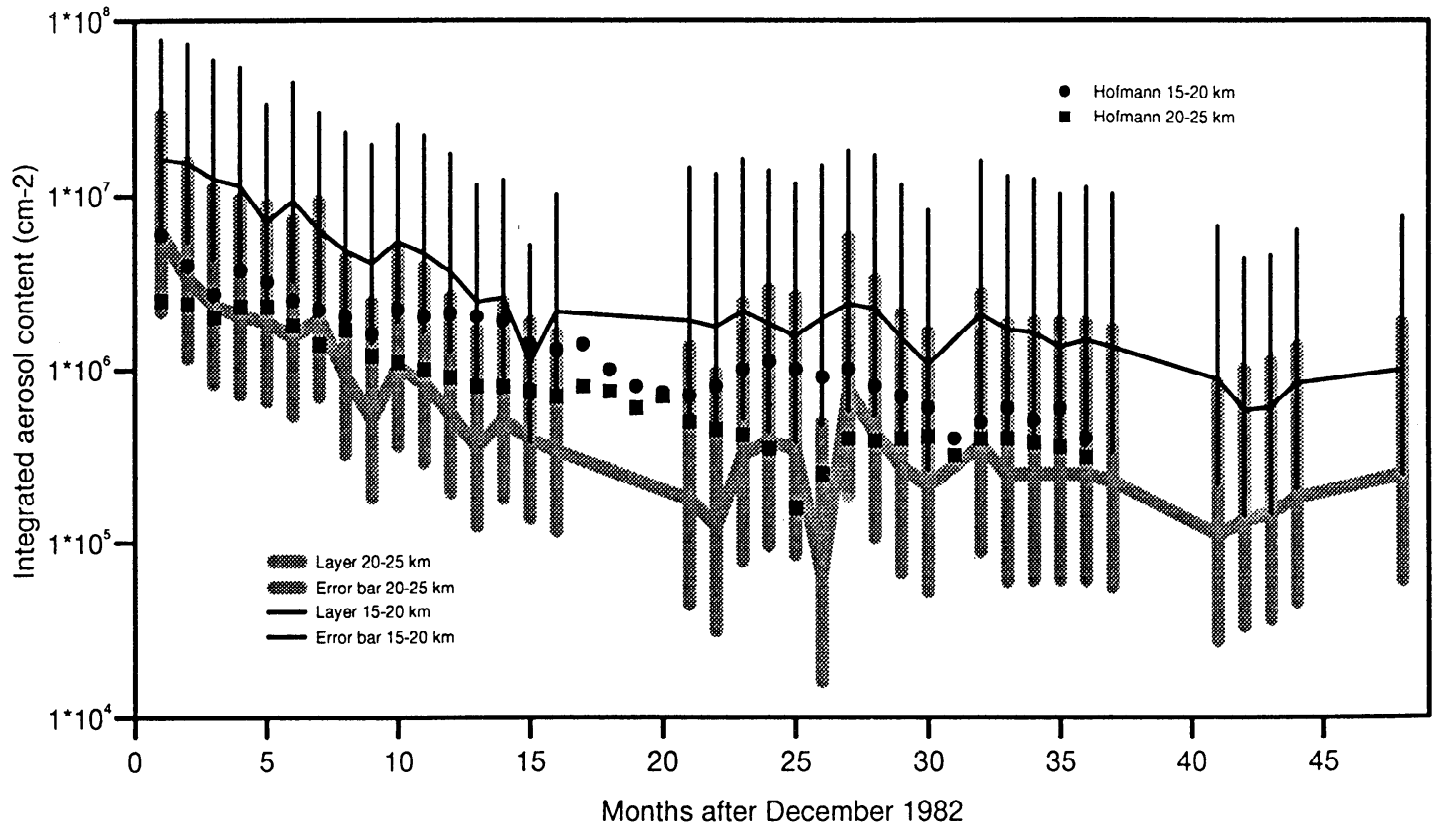

Figure 8. Temporal evolution of the integrated stratospheric aerosol content for various altitude layers (15-20 and $20-25 \mathrm{~km}$ ) for the El Chichon event as derived from lidar and in situ balloon measurements. 


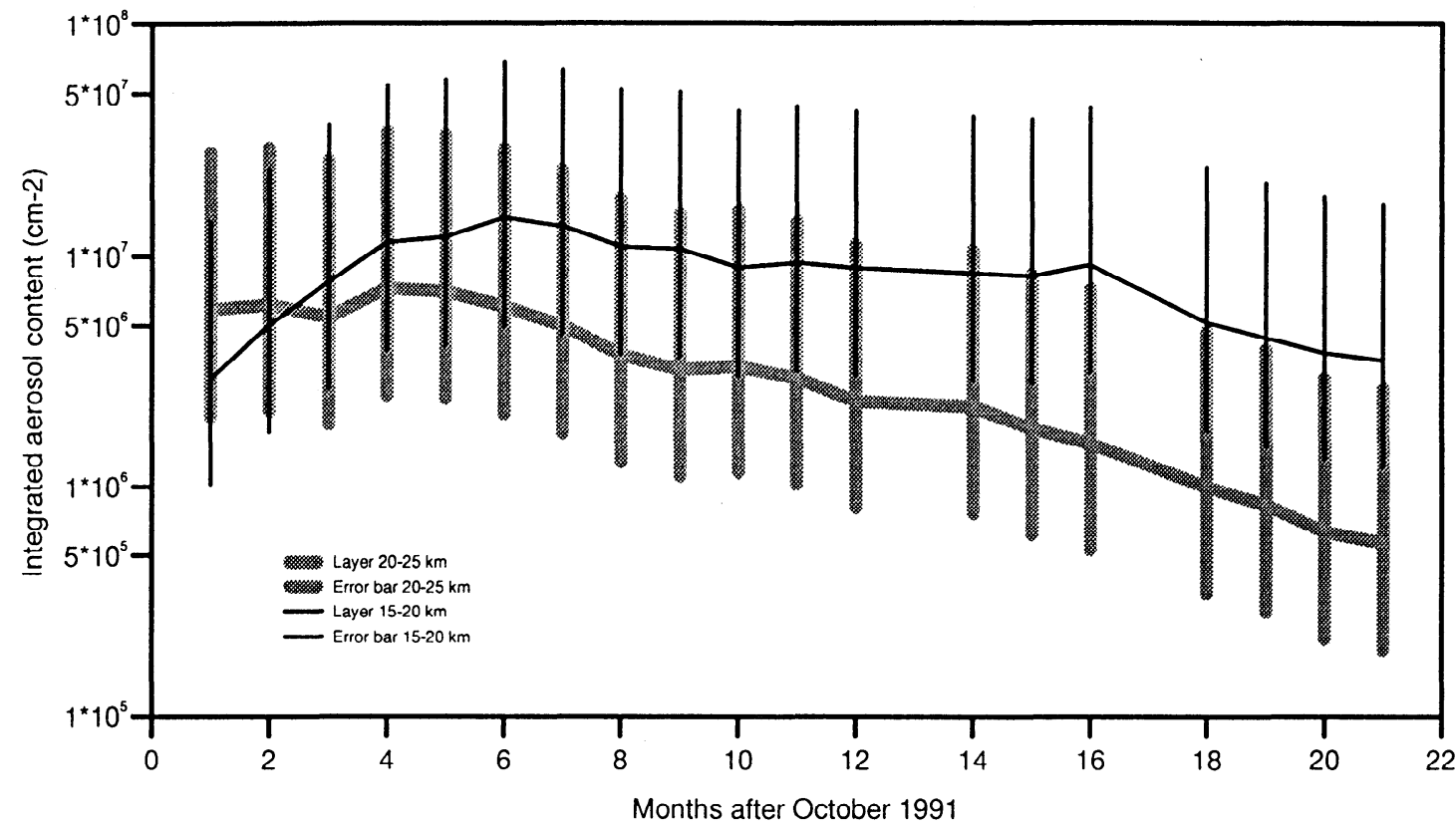

Figure 9. Temporal evolution of the integrated stratospheric aerosol content for various altitude layers (15-20 and $20-25 \mathrm{~km}$ ) for the Mount Pinatubo event as derived from lidar measurements.

with different values of $\bar{r}$ and $\overline{r^{2}}$, to take into account the range of uncertainties in the derived size parameters of the particles.

The results of these calculations are compared with the experimental data on Figure 10 (El Chichon) and Figure 11 (Mount Pinatubo). In the lower layer, the agreement is rather good between the calculated and measured values, accounting also for the observed difference in the residence times for the two volcanic eruptions. In the upper layer, although the general behaviour of the sedimentation of the particles is still correctly described, the model overestimates the observed residence times. These discrepancies can be related to four main causes. First, the precision on the retrieved size parameters of the particles is reduced in the above layer, due to the lower scattering and a less accurate inversion of the lidar data. Second, the coalescence processes have not been taken into account in this simple model, which can have larger effects in the upper layer, where no downward particle flux is assumed at the upper boundary. Third, the considered mean values of the eddy diffusion coefficient $K_{z}$ do not take into account its altitude variability in the two layers $15-20$ and $20-25 \mathrm{~km}$. The fourth cause is related to the assumption made in this calculation of a monomodal, altitude independent, size distribution of the particles. Following observations made after the El Chichon and

Table 3. Values of the Surface Area per Unit Volume of Stratospheric Aerosol Particles in the Altitude Range from 15 to 20 and 20 to $25 \mathrm{~km}$, for 3 Periods of Time Following the El Chichon and Mount Pinatubo Eruptions

\begin{tabular}{ccc}
\hline Period & $\begin{array}{c}\mathrm{S}\left(\mu \mathrm{m}^{2} \cdot \mathrm{cm}^{-3}\right) \\
15-20 \mathrm{~km}\end{array}$ & $\begin{array}{c}\mathrm{S}\left(\mu \mathrm{m}^{2} \cdot \mathrm{cm}^{-3}\right) \\
20-25 \mathrm{~km}\end{array}$ \\
\hline El Chichon 1983 & $9.2-42$ & $2.6-15.5$ \\
El Chichon 1984-1985 & $1.9-4.5$ & $0.4-0.9$ \\
Mount Pinatubo 1991-1993 & $6.7-32$ & $1.3-16$ \\
\hline
\end{tabular}

Mount Pinatubo eruptions, bi-modal, altitude dependent size distributions can be observed [Jäger and Carnuth, 1987; Jäger, 1992]. If one considers that as much as 15 to $20 \%$ of the particles can be in the larger size mode in the upper layer, the resulting increase in the sedimentation velocity is very likely to explain the shorter residence time when compared to the model results. In the lower layer, as less as $10 \%$ of the particles are in the larger size mode, the effect of the bi-modal size distribution on the sedimentation velocity is reduced and accounted for by the range of uncertainties in the $\bar{r}$ and $\overline{r^{2}}$ values. Nevertheless, the simple one-dimensional box model developed here, accounts quite reasonably for the 4 months longer residence time observed for the Mount Pinatubo eruption. This increase is thus clearly related to the different initial vertical distribution of the aerosol cloud in the upper altitude range.

\section{Conclusion}

Long-term observations of the stratospheric aerosol layers have been conducted since 1981 at the Observatoire de HauteProvence as part of the Network for Detection of Stratospheric Change. These lidar observations cover the period following the major eruptions of the last decades, that is, El Chichon volcano

Table 4. Values of the Sedimentation Velocities of the Stratospheric Aerosol Particles in the Altitude Range from 15 to 20 and 20 to $25 \mathrm{~km}$, for 3 Periods of Time Following the El Chichon and Mount Pinatubo Eruptions

\begin{tabular}{ccc}
\hline Period & $\begin{array}{c}\mathrm{V}\left(\mathrm{cml} . \mathrm{s}^{-1}\right) \\
15-20 \mathrm{~km}\end{array}$ & $\begin{array}{c}\mathrm{V}\left(\mathrm{cm} . \mathrm{s}^{-1}\right) \\
20-25 \mathrm{~km}\end{array}$ \\
\hline El Chichon 1983 & $6.310^{-3}$ & $1.110^{-2}$ \\
El Chichon 1984-1985 & $5.110^{-3}$ & $9.210^{-3}$ \\
Mount Pinatubo 1991-1993 & $8.310^{-3}$ & $1.310^{-2}$ \\
\hline
\end{tabular}




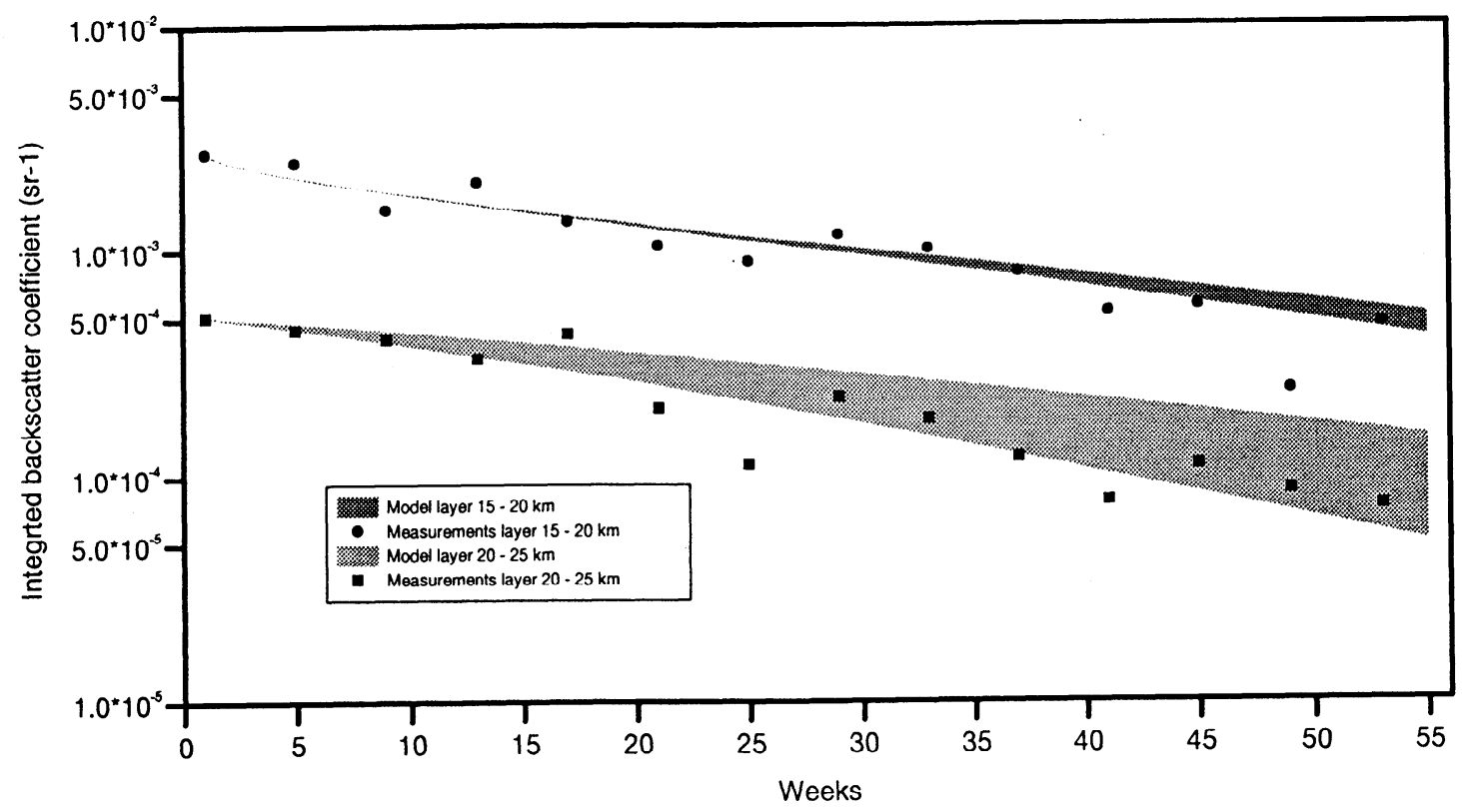

Figure 10. Comparison of the calculated and observed values of the integrated backscatter coefficient between 15-20 and 20-25 km for the El Chichon event.

in 1982 and Mount Pinatubo in 1991, allowing thus a detailed comparison of these two events. From the inversion of the lidar backscattered signals, and from ancillary balloon measurements, the temporal evolution of the optical and geometrical properties of the aerosol particles have been retrieved for both eruptions. Although the eruption of Mount Pinatubo has led to the injection of twice as much sulphur dioxide than the El Chichon event, the observed backscatter coefficient and altitude integrated backscatter at the Observatoire de Haute-Provence have been shown to be similar for the two eruptions. This is most likely related to the fact that the eruptions occurred at different phases of the quasi-biennal oscillation, leading thus to a global spread out of the Mount Pinatubo cloud, while the El Chichon particles were only dispersed mainly over the northern hemisphere. The phase function of the aerosol backscatter has been directly determined from the lidar data using a new algorithm, derived from the general Klett method. The phase function has then been shown to vary with time for the El Chichon event, in the 2 years following the eruption, accounting thus for the modifications in the size distribution of the particles. The retrieved size parameters of the aerosol particle, mean radius, and surface areas are also shown to be rather similar for the two eruptions. A large difference is however measured in the residence time of the particles below $20 \mathrm{~km}$. While the residence times for the upper layers, that is, above $20 \mathrm{~km}$, are similar (7 - 8 months), the observed residence time for the Mount Pinatubo particles

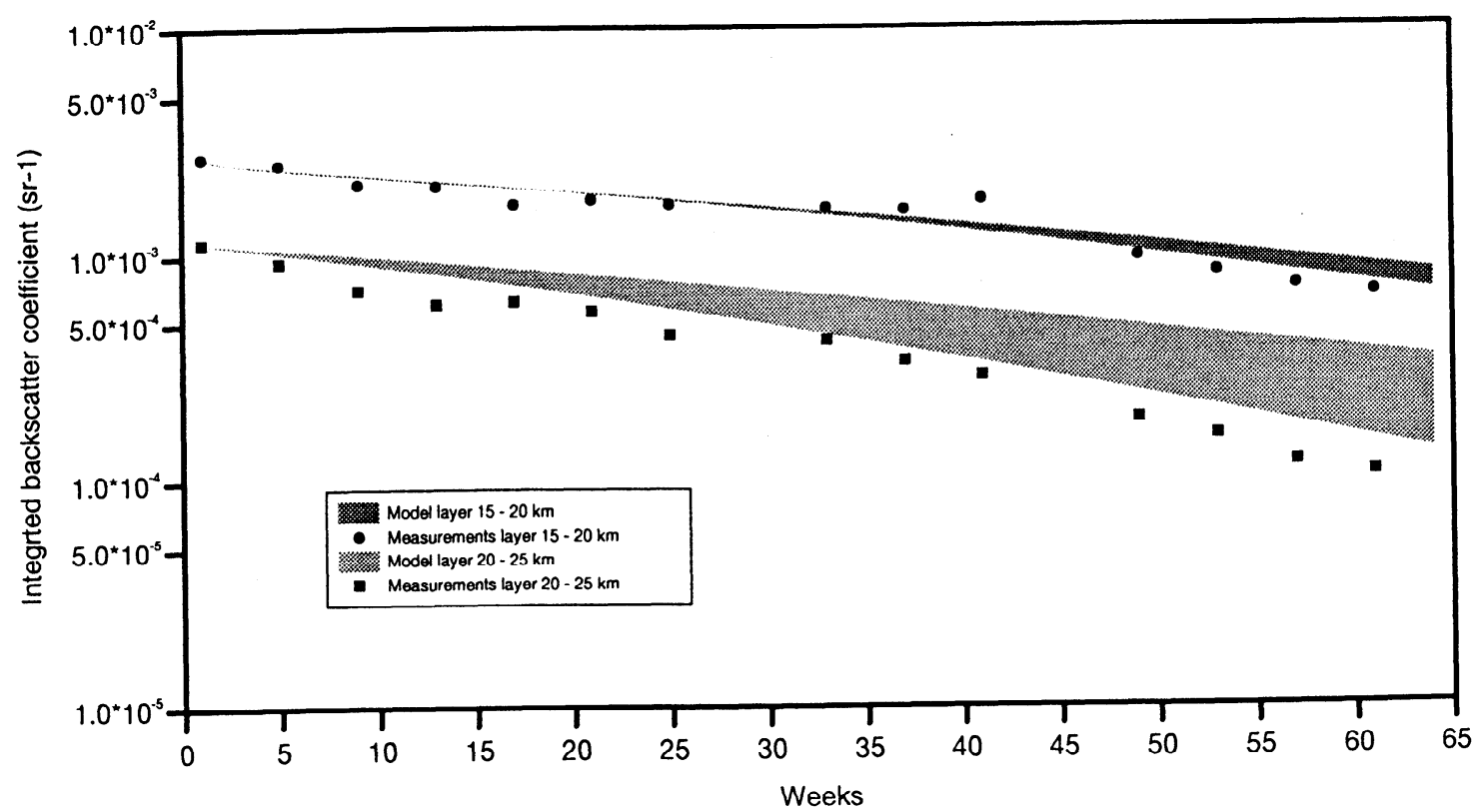

Figure 11. Comparison of the calculated and observed values of the integrated backscatter coefficient between $15-20$ and $20-25 \mathrm{~km}$ for the Mount Pinatubo event. 
below $20 \mathrm{~km}$ is 12 months, as compared to 8 months only for the $\mathrm{El}$ Chichon cloud. This difference is quantitatively accounted for using a simple one-dimensional box model, based on the sedimentation velocities calculated from the particle geometrical properties. The longer residence time is then clearly related to the different vertical extent of the Mount Pinatubo cloud, reaching much higher altitude than the El Chichon aerosols. Taking into account its global impact and this longer residence time of the particles in the lower stratosphere, the Mount Pinatubo eruption can undoubtedly be identified as the major eruption of the last decades, because of both its climatic and chemical impacts.

\section{Appendix}

The uncertainties on the particular backscatter coefficient $\beta(z)$ can be analytically expressed as a function of the lidar signal $S(z)$ of the value of the backscatter coefficient at the reference altitude $z_{t}$ and of the backscatter phase function $\varphi_{p}$. The variances of these three error sources are calculated starting from (7) written as

$$
\beta(z)=\frac{N(z)}{D(z)}
$$

where : $\quad N(z)=\left(z-z_{0}\right)^{2} \cdot Q(z) \cdot S(z)$

and :

$$
D(z)=\frac{\left(z_{t}-z_{0}\right)^{2} \cdot S\left(z_{t}\right)}{\beta\left(z_{t}\right)}
$$

$$
+\frac{2}{\varphi_{p}} \cdot \int_{z}^{z_{t}}\left(z^{\prime}-z_{0}\right)^{2} \cdot S\left(z^{\prime}\right) \cdot Q\left(z^{\prime}\right) \cdot d z^{\prime}
$$

The variance associated with the signal $S(z)$ is given by

$$
\begin{aligned}
\operatorname{var}(\beta(z))=\frac{1}{D(z)} & \cdot\left(\operatorname{var}(N(z))+\beta(z)^{2} \cdot \operatorname{var}(D(z))\right. \\
+ & 2 \beta(z) \cdot \operatorname{cov}(N, D))
\end{aligned}
$$

with :

$$
\begin{aligned}
\operatorname{var}(N(z)) & =\left(z-z_{0}\right)^{2} \cdot Q(z)^{2} \cdot \operatorname{var}(S(z)) \\
\operatorname{var}(D(z)) & =\left[\frac{\left(z_{t}-z_{0}\right)^{2}}{\beta\left(z_{t}\right)}+\frac{4\left(z_{t}-z_{0}\right)^{4}}{\varphi_{p}^{2}}+\frac{4 \Delta z \cdot\left(z_{t}-z_{0}\right)^{4}}{\varphi_{p} \cdot \beta\left(z_{t}\right)}\right] \operatorname{var}\left(S\left(z_{t}\right)\right) \\
& +\frac{4 \Delta z}{\varphi_{p}^{2}} \cdot \int_{z}^{z_{t}}\left(z^{\prime}-z_{0}\right)^{2} \cdot Q\left(z^{\prime}\right)^{2} \cdot \operatorname{var}\left(S\left(z^{\prime}\right)\right) \cdot d z^{\prime}
\end{aligned}
$$$$
\operatorname{cov}(N, D)=-\frac{4}{\varphi_{p}^{2}} \cdot\left(z-z_{0}\right)^{2} \cdot Q(z)^{2} \cdot \Delta z \cdot \operatorname{var}(S(z))
$$

The variance associated with the reference altitude, $\beta\left(z_{t}\right)$ is given by

$$
\operatorname{var}(\beta(z))=\frac{1}{D(z)}\left(\operatorname{var}(N(z))+\beta(z)^{2} \operatorname{var}(D(z))+2 \beta(z) \operatorname{cov}(N D)\right)
$$

The variance associated with the phase function $\varphi_{p}$ is obtained as

$$
\begin{aligned}
& \operatorname{var}(\beta(z))=\left[\frac{2 \beta(z)}{\varphi_{p}^{2}}\right] \cdot \operatorname{var}\left(\varphi_{p}\right) \cdot\left[-\int_{z}^{z_{t}} \beta_{m}\left(z^{\prime}\right) \cdot d z^{\prime}\right. \\
& \left.+\frac{1}{D(z)} \cdot \int_{z}^{z_{t}}\left(\left(z^{\prime}-z_{0}\right) \cdot Q\left(z^{\prime}\right) \cdot S\left(z^{\prime}\right)\right) \cdot\left(1+2 \frac{\int_{z^{\prime}}^{z_{t}} \beta_{m}\left(z^{\prime \prime}\right) \cdot d z^{\prime \prime}}{\varphi_{p}}\right) \cdot d z^{\prime}\right]^{2}
\end{aligned}
$$

\section{References}

Ackerman, M.. et al., European validation of SAGE II aerosol profiles, J. Geophys. Res., 94 (D6), 8399-8411, 1989.

Adriani, A., F. Congeduti, G. Fiocco, and G.P. Gobbi, One year lidar observation of the stratospheric aerosol at Frascati, March 1982 - March 1983, Geophy. Res. Lett., 14 (11), 1005-1008, 1983.

Brasseur, G. and, S. Solomon, Aeronomy of the Middle Atmosphere, D. Reidel, Norwells, Mass. , 1984.

Chedin, A., N.A. Scott, C. Wahiche, and P. Moulinier, The Improved Initialisation Inversion method : A high-resolution physical method for temperature retrievals from satellites of the TIROS-N series, J. Clim. Appl. Meteorol., 24 (2), 128-143,1985.

Deshler, T., B.J. Johnson, and W.R. Rozier, Balloonborne measurements of Pinatubo aerosol during 1991 and 1992 at $41^{\circ} \mathrm{N}$ : Vertical profiles, size distribution, and volatility, Geophys. Res. Lett., 20 (14), 1435-1438, 1993.

Granier, C., and G. brasseur, Impact of heterogeneous chemistry on model predictions of ozone changes, J. Geophys. Res., 97 (D16), 18,015 18,033, 1992.

Hofmann, D.J., and J.M. Rosen, Stratospheric sulphuric acid fraction and mass estimate for the 1982 volcanic eruption of El Chichon, Geophys. Res. Lett., 10 (4), 313-316, 1983.

Hofmann, D.J., and J.M. Rosen, On the temporal variation of stratospheric aerosol size and mass during the first 18 months following the 1982 eruption of El Chichon, J. Geophy. Res., 89 (D3), 4883-4890, 1984a.

Hofmann, D.J., and J.M. Rosen, Time variation of the stratospheric aerosols size distribution after the eruption of El Chichon, Proceedings Int. Rad. Symp., Perugia, Italy, pp 21-28, edited. by G. Fiocco, pp 111-114, A. Deepak Hampton, Va., 1984b.

Hofmann, D.J., and J.M. Rosen, On the prolonged lifetime of the El Chichon sulphuric acid aerosol cloud, J. Geophys. Res., 92 (D8), 9825-9830, 1987.

Jäger, H., The Pinatubo eruption cloud observed by lidar at GarmischPartenkirchen, Geophys. Res. Lett.,19 (2), 191-194, 1992.

Jäger, H., and W. Carnuth, The decay of the El Chichon stratospheric perturbation, observed by lidar at northern mid-latitudes, Geophys. Res. Lett., 14 (7), 696-699, 1987.

Jäger, H., and D.J. Hofmann, Mid-latitude lidar backscatter to mass, area and extinction conversion model based on in situ aerosol measurements from 1980 to 1987, Appl. Opt., 30 (1), 127-138, 1991.

Klett, J.D., Stable analytical inversion solution for processing lidar returns, Appl. Opt., 20 (2), 211-220, 1981

Klett, J.D., Lidar inversion with variable backscatter/extinction ratios, Appl.Opt., 24 (11), 1638-1642, 1985.

Labitzke, K., B. Naujokat, and M.P. McCormick, Temperature effects on the stratosphere of April 4, 1982 eruption of El Chichon, Mexico, Geophys. Res. Lett., 10 (xx), 24-26, 1983.

Labitzke, K., and M.P. McCormick, Stratospheric temperature increases due to Pinatubo aerosols, Geophys. Res. Lett., 19 (2), 207-210, 1992.

Lenoble, J., and C. Brogniez, A comparative review of radiation aerosol models, Beitr. Phys. Atmos., 57 (1), 1-20, 1984.

Lenoble J., C. Brogniez, and P. Pruvost, Radiative characteristics of stratospheric aerosols from SAGE data, Proceedings Int. Rad. Symp., Perugia, Italy, 2, edited. by G. Fiocco, pp 156-158, A. Deepak Hampton, Va., 1984.

Menzies, R.T., and D.M. Tratt, Evidence of seasonally dependent stratosphere-troposphere exchange and purging of lower stratospheric aerosol from a multiyear lidar data set, J. Geophys. Res., 100 (D2), 3139-3148, 1995. 
McCormick, M.P., and R.E. Veiga, SAGE II measurements of early Pinatubo aerosols, Geophys. Res. Lett., 19 (2), 155-158, 1992.

Measures, R.M., Laser remote sensing, edited by Wiley Interscience, New York, 1984.

Michalsky, J.J., B.M. Herman, and N.R. Larson, Mid-latitude stratospheric aerosol layer enhancement by El Chichon : the first year, Geophys. Res. Lett., 11 (1), 76-79, 1984.

Palmer, K.F., and D. Williams, Optical constants of sulphuric acid; application to the clouds of Venus, Appl. Opt., 14 (21), 208-219, 1975.

Rosen, J.M., and D.I. Hofmann, Optical modelling of stratospheric aerosols : present status, Appl. Opt., 25 (3), 410-419, 1986.

Russell, P.B., J. Swissler, and M.P. McCormick, Methodology for error analysis and simulation of lidar aerosol measurements , Appl. Opt., 18 (22), 3783-3797, 1979

Shibata, T., M. Fujiwara, and M. Hirono, The El Chichon volcanic cloud in the stratosphere : lidar observation at Fukuoka and numerical simulation, J. Atmos. Terrestr. Phys., 46 (12), 1121-1146, 1984.

Thomas, L., D.B. Jenkins, D.P. Wareing, G. Vaughan and M. Farrington, Lidar observation of stratospheric aerosols associated with the El Chichon eruption, Ann. Geophys., 5 (1), 47-56, 1987.

Trepte, C.R., R.E. Veiga, and M.P. McCormick, The poleward dispersion of Mount Pinatubo volcanic aerosols, J. Geophys. Res., 98 (D10), 18,563$18,573,1993$.
Whitten, R.C., Topics in current physics, The Stratospheric Aerosol Layer, edited by R.C. Whitten, pp 1-12, Springer-Verlag, Berlin Heidelberg New York, 1982.

Young, R.E., H. Houden, O.B. Toon, Radiatively forced dispersion of the Mt. Pinatubo volcanic cloud and induced tempcrature perturbations in the stratosphere during the first few months following the eruption, Geophys. Res. Let., 21 (5), 369-372, 1994.

P. Chazette, now at Laboratoire de Modélisation du Climat et de l'Environnement, Institut Pierre-Simon-Laplace, C.E. Saclay - Bât. 709 Orme des Merisiers, 91191 Gif sur Yvette Cedex, France (e-mail : pch@asterix.saclay.cca.fr).

C. David, J. Lefrère, S. Godin, J. Pelon and G. Mégie, Service d'Aéronomie du CNRS, Institut Pierre-Simon-Laplace, Université Pierre-etMarie-Curie - B 102, 4, Place Jussieu - 75232 Paris Cedex 05, France

(Received February 2, 1995; revised May 7, 1995; accepted July 20, 1995) 